\section{Effect of Substrate Concentration on the Inactivation Velocity of Carp Muscle 5'-Nucleotidase by EDTA*1}

Short Paper

In the previous paper, ${ }^{1 /}$ it was found that, in the presence of 5'-AMP and EDTA, the inactivation of carp 5'-nucleotidase proceeded time-dependently according to the following equation;

$\log \mathrm{V}_{t} / \mathrm{V}_{0}=-k[$ EDTA $t$

where $V_{0}$ or $V_{t}$ was enzymatic reaction velocity at an incubation time $o$ or $t$. It was also found that, with increasing concentration of 5'-AMP, a rate constant $k$ in eq. (1) converged to a smaller value than that observed in the absence of 5'-AMP. In order to account for these experimental results, the present report deals with a kinetic consideration on the inactivation of $5^{\prime}$-nucleotidase by EDTA in the presence of various concentration of 5 -AMP.

The experimental result reported in the previous paper is assumed to be caused by the following mechanisms. i) When the mixture of carp muscle 5' nucleotidase (E), substrate (S), and EDTA is incubated, the removal of bound metal from $E$ and that from 5 -nucleotidase-substrate complex (ES) should occur time-dependently and respectively. ii) The rate con$\operatorname{stant}(k)$ of the removal of bound metal by EDTA from E should be different from the rate constant $\left(k_{s}\right)$ of that from ES. iii) The metal-free 5 -nucleotidase thus formed should have no enzymatic activity or be incapable of binding with substrate.

Rates of the removal of bound metal, $v_{0}$ and $v_{x}$, in this reaction mixture, can be written as follows;

$$
\begin{aligned}
& v_{o}=k_{o}[\mathrm{E}][\mathrm{EDTA}] \\
& v_{s}=k_{s} \text { [ES][EDTA] }
\end{aligned}
$$

It is reasonable to suppose from the previous experimental result that $k_{o}$ is larger than $k_{s}$. Then if the removal of bound metal proceeds followed only by eq. (2) and (3), [E]/[ES] may gradually decrease. In this reaction mixture, however, following equation must simultaneously be satisfied;

$$
[\mathrm{E}][\mathrm{S}] /[\mathrm{ES}]=\mathrm{Km}
$$

where $\mathrm{Km}$ is the Michaelis constant. The decrease of [E]/[ES] should be compensated by the dissociation of $E S$ to $E$ and $S$. The change of $[E]$ and $[E S]$ in a minute time, $d t$, should be expressed as follows;

$$
\begin{array}{r}
d[\mathrm{E}]=-k_{\mathrm{o}} \text { [EDTA][E]dt }+\alpha \\
d[\mathrm{ES}]=-k_{\mathrm{s}}[\mathrm{EDTA}][\mathrm{ES}] d t-\alpha
\end{array}
$$

where $\alpha$ is the change of [E] in $d t$ by the dissociation of ES.

By rearranging eqs. (4), (5), and (6) for [ES], the following equation is obtained;

$d[\mathrm{ES}] /[\mathrm{ES}]=-\left\{k_{o}+\left(k_{\mathrm{z}}-k_{o}\right) /(1+\mathrm{Km} /[\mathrm{S}])\right\}[\mathrm{EDTA}] d t$ and the integrated form of this equation is

$$
\begin{aligned}
& \log \left[\mathrm{ES}_{\ell}\right] /\left[\mathrm{ES}_{o}\right] \\
& \quad=-\left\{k_{o}+\left(k_{s}-k_{o}\right) /(1+\mathrm{Km} /[\mathrm{S}])\right\}[\mathrm{EDTA}] t
\end{aligned}
$$

(Accepted June 30, 1984)

*1 EDTA によるコイ筋肉 5’ヌタレオチダーゼ不

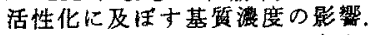

*2 畐网和子：奈度教育大学, 奈良市高畑町。

*3兄本裕美・缥藤金次：奈良女子大学家政学部, 奈 度南北角屋西町。

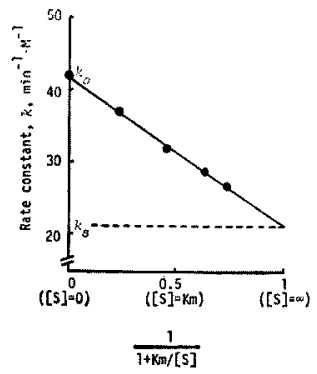

Fig. 1. Effect of $5^{\prime}$-AMP concentration on the rate constant $k$ in the inactivation of carp muscle $5^{\prime}$-nucleotidase by EDTA.

The change in absorbance at $260 \mathrm{~nm}$ was continuously recorded during the incubation at $20^{\circ} \mathrm{C}$ of reaction mixture which contained various concentration of $5^{\prime}$-AMP, $1 \mathrm{mM}$ EDTA, $5^{\prime}$ nucleotidase, ${ }^{2)}$ and an excess of adenosine deaminase. From the slopes on the recorded curve at various incubation times or enzymatic reaction velocities, $k$ in eq. (1) was calculated. A Km value of $9.3 \times 10^{-5} \mathrm{M}^{1)}$ was used.

where $\left[\mathrm{ES}_{0}\right]$ or $\left[\mathrm{ES}_{t}\right]$ is concentration of ES at an incubation time $o$ or $t$. As the $S^{\prime}$-nucleotidase reaction velocity is proportional to [ES], eq. (7) is rewritten as follow;

$$
\begin{aligned}
& \log \mathrm{V}_{t} / \mathrm{V}_{o} \\
& \quad=-\left(k_{o}+\left(k_{\mathrm{s}}-k_{o}\right) /(1+\mathrm{Km} /[\mathrm{S}])\right\}[\mathrm{EDTA}] t
\end{aligned}
$$

On referring to eqs. (1) and (8), the following equation is obtained;

$$
k=k_{o}+\left(k_{s}-k_{o}\right) /(1+\mathrm{Km} /[\mathrm{S}])
$$

In order to verify this equation, $k$ values obtained in the previous paper were plotted against $(1+\mathrm{Km} /$ $[\mathrm{S}])^{-1}$. As shown in Fig. 1, a straight line was obtained, and values of $k_{o}$ and $k_{s}$ were read to be 41 and $21 \mathrm{~min}^{-1} \cdot \mathrm{M}^{-1}$ respectively.

This figure shows that the inactivation of 5 -nucleotidase proceeds according to eq. (8) in the presence of EDTA and $5^{\prime}$-AMP, and that $k_{\mathrm{o}}$ is larger than $k_{\mathrm{s}}$. This indicates that the stability of metal-apoenzyme binding is increased by the formation of enzymesubstrate complex. It is also reasonable to suppose that the metal which is removed by EDTA may bind to apoenzyme at a position, where a conformational change is caused by the formation of enzyme-substrate complex, that is, at a position closely related to enzyme-substrate binding site.

Kazuko ToMloka, ${ }^{* 2}$ Hiromi YamaMoto, ${ }^{* 3}$ and Kinji ENDO*3

*2Nara University of Education, Nara 630, Japan.

*3Faculty of Home Economics, Nara Women's University, Nara 630, Japan.

\section{References}

1) K. TomiokA and K. Endo: Bull. Japan. Soc. Sci. Fish., 50, 1739-1744 (1984).

2) K. TomiokA and K. Endo: Bull. Japan. Soc. Sci. Fish., 50, 1077-1081 (1984). 